\title{
LA OTRA ORILLA Y SONAMBULARIO: PARALELISMOS EN LA VERTIENTE FANTÁSTICA DE JULIO CORTÁZAR Y JULIO RAMÓN RIBEYRO
}

\section{LA OTRA ORILLA AND SONAMBULARIO: PARALLELS IN THE FANTASTIC ASPECT OF JULIO CORTÁZAR AND JULIO RAMÓN RIBEYRO}

\section{Gustavo QUICHIZ CAMPOS}

Universidad de Zaragoza gaquichizc@gmail.com

Resumen: El estudio de lo fantástico en Julio Ramón Ribeyro (1927-1994) es todavía un trabajo por terminar, del mismo modo que lo es Sonambulario, su proyecto de libro que tenía por objetivo reunir los cuentos fantásticos de la primera etapa de su obra, pero que finalmente abandonó. Escritor célebre en el Perú, y de culto fuera de allí, vivió la mayor parte de su vida en París. Fue amigo de Julio Cortázar (1914-1984), con quien compartía su modo de entender lo fantástico. Este trabajo contrasta parte de los primeros cuentos de ambos escritores y la importancia que estos revelan en la definición de la literatura fantástica hispanoamericana del siglo XX.

Palabras clave: Julio Ramón Ribeyro; Julio Cortázar; «La huella»; «Mudanza»; La otra orilla; Sonambulario.

Abstract: The study of the fantastic in Julio Ramón Ribeyro (1927-1994) is still a work in progress, in the same way that Sonambulario is, his book project that aimed to gather the fantastic short stories of the first stage of his work, but that he finally dropped. A famous writer in Peru, and with cult following outside there, Ribeyro lived most of his life in Paris. He was a friend of Julio Cortázar (1914-1984), with whom he shared his way of understanding the fantastic. This paper contrasts the first short stories of both writers and the importance they reveal in the definition of twentieth-century Hispanic America fantasy literature.

Keywords: Julio Ramón Ribeyro; Julio Cortázar; «La huella»; «Mudanza»; La otra orilla; Sonambulario. 
$\mathrm{L}$

a obra de Julio Ramón Ribeyro está asociada, sobre todo, a una narrativa breve hecha a espaldas de la parafernalia del boom por la novela, la política y la atención a los acontecimientos históricos y movimientos colectivos. La suya, en cambio, estaba puesta en hablar de una realidad irredimible, de personajes opacos atrapados en empresas imposibles que solo les conducirían a la frustración. «En Ribeyro, como en otros de los mejores escritores peruanos, el pesimismo no es una inclinación personal que pueda resolverse en datos psicológicos o biográficos, sino una manera de ser dignamente ante la realidad del sufrimiento» (Loayza, 1993: 174).

Ribeyro, sin embargo, no se reconocía pesimista, sino escéptico, y se le podría añadir individualista, anacrónico. Como él, su prosa era parca, concisa, exacta, y si bien su estilo se caracteriza por eludir casi cualquier tipo de experimentalismo - Vargas Llosa decía de Ribeyro que «la transparencia de su estilo es engañosa» (1996: 264)—, su concepción de lo fantástico se puede comparar a la de los grandes autores hispanoamericanos del siglo XX, concretamente a la de Julio Cortázar, en quien Ribeyro encontraba no solo un referente: «En parte comparto la teoría de Cortázar de que lo "mágico" está en lo cotidiano, en nuestra realidad» (Ribeyro, 2015: 231), sino una influencia obligada: «La verdad es que en esos cuentos [los fantásticos] hay otras resonancias, que van desde Poe hasta Cortázar» (Luchting, 1988: 365). Si bien habría que aclarar que más que una influencia existía una sintonía de época entre ambos, dado que tanto Ribeyro como Cortázar encontraron en el cuento fantástico una de las herramientas para esclarecer una realidad que se presentaba como «un fenómeno tan difuso que es difícil distinguirla del sueño, la fantasía o la alucinación» (Ribeyro, 2007: 14).

En palabras de Ribeyro, sus cuentos fantásticos «están siempre apoyados en hechos reales [...], pero en los cuales hay siempre un momento en que la historia se dispara un poco hacia lo insólito o inesperado» (2015: 298), es decir, lo fantástico no sería solo un evento que irrumpe en la aparente realidad mimética de la historia, sino que su aparición la reconstruye, entremezclándose con ella. Este modo de practicar lo fantástico, que consiste más en el cuestionamiento de la propia realidad que en la exageración de lo sobrenatural, es aquel que otros autores han reconocido como fantástico posmoderno o neofantástico, si bien esto significaría olvidar que una de las características esenciales de lo fantástico a lo largo de la historia de la literatura es su constante evolución con el objetivo de «despertar el interés de unos lectores (y espectadores) que, con el paso del tiempo, conocen cada vez mejor las convenciones formales y temáticas de lo fantástico y, por tanto, se dejan sorprender con menos facilidad» (Roas, 2011: 114).

Con todo, la vertiente fantástica de Ribeyro ha estado siempre a la sombra de la atención que tanto la crítica como el público han enfocado en la dimensión realista de su obra. La razón más evidente para explicar este hecho tal vez se encuentre en las escasas incursiones del autor en lo fantástico, cuyo corpus, que a día de hoy aún dista de estar cerrado, apenas sobrepasa la decena de los noventa y cinco 
cuentos que componen toda su narrativa breve ${ }^{1}$. Sin embargo, pese a este ejercicio intermitente, Ribeyro empieza y, en cierta manera, termina escribiendo cuentos fantásticos ${ }^{2}$.

Cuentos olvidados es el subtítulo que agrupa actualmente los seis cuentos que componen la protohistoria literaria de Ribeyro. Fueron rescatados póstumamente por Jorge Coaguila en Ribeyro, la palabra inmortal (1995), pero aparecen actualmente también reunidos bajo el título de Cuentos olvidados en las últimas ediciones de La palabra del mudo, volumen que recoge sus cuentos completos.

Publicados entre 1949 y 1956 en diarios y revistas peruanos, el redescubrimiento de esta colección de cuentos ha supuesto pasar de un problema macrotextual a uno microtextual, pues incluso en este pequeño corpus los análisis sobre cuáles son los verdaderamente fantásticos no son claros ni definitorios ${ }^{3}$. Cuentos completos está compuesto por «La vida gris», que abre la colección y es el único de cariz realista; los fantásticos «La huella» $\mathrm{y}$ «El cuarto sin numerar», a los que se debería añadir «El caudillo», teñido por la alegoría. «La careta» y «La encrucijada», por otra parte, no deberían considerarse fantásticos, sino ejemplo de lo que se conoce como grotesco y maravilloso. Estos dos últimos cuentos comparten con lo fantástico la presencia de lo sobrenatural, si bien dejan de lado que «lo fantástico exige una condición más: la transgresión de las leyes del mundo real objetivo» (Rodríguez Pequeño, 1991: 147).

Con todo, ninguno de ellos fue recogido por el autor en sus posteriores obras dado su carácter «ostensiblemente imitativo» (Luchting, 1988: 365). Las sombras de Poe y Kafka se proyectan en estos primeros cuentos del escritor peruano, destacando la del último, cuya influencia no sorprende cuando se observa que la juventud de Ribeyro coincide con las primeras traducciones de los libros de Kafka en Argentina ${ }^{4}$. Como ha declarado el propio autor, en esa época de aprendizaje lo normal era «tratar de escribir conforme al estilo del escritor que en ese momento estaba de moda, que para nosotros era Kafka» (2015: 97).

Sin embargo, el olvido al que Ribeyro condenó a estos textos no fue del todo cierto desde un principio, pues, como señala en su diario, por un momento quiso incluso agruparlos bajo un solo libro: «Quiero [...] aprovechar los cuatro o cinco cuentos que he publicado en revistas o diarios y que están amenazados de dispersión. Será un librito discreto titulado Sonambulario» (2003: 98; 12-02-1956). El plan de Ribeyro era completar este grupo de cuentos con otros que se dedicó a escribir en las siguientes semanas. No obstante, cancelaría el proyecto poco más de un mes después, al concluir que los últimos

\footnotetext{
${ }^{1}$ Como ejemplo pueden verse los diferentes corpus de cuentos fantásticos de Ribeyro propuestos por Vidal (1975: 76), Minardi (2002: 74), Martínez (2008: 261) o Rodero (2015: 23).

2 «El libro en blanco»y «Nuit caprense cirius illuminata», escritos ambos en 1993, son los últimos cuentos publicados por Ribeyro en vida. No obstante, no se puede decir que sean los últimos que escribió, pues en la última edición de La palabra del mudo, volumen que recoge toda su narrativa breve, aparece el inédito «Surf», relato autobiográfico escrito en 1994, solo meses antes de su muerte.

${ }^{3}$ Entre los aún escasos análisis de estos cuentos destacan los de González Montes (2010), Vandoorne (2011), Susti (2013) o Narbona (2016).

${ }^{4}$ En Hispanoamérica, «en consonancia con lo que sucedía en otras latitudes, a lo largo de las décadas del cuarenta y del cincuenta se fue publicando en Argentina su obra completa, fundamentalmente en la editorial Emecé, tras la aparición primera en formato de libro de La metamorfosis y El proceso desde la también argentina Losada a finales de los años treinta» (Martínez Salazar y Yelin, 2013: 19).
} 
se parecían mucho entre ellos. Hubiera sido su segundo libro de cuentos tras Los gallinazos sin plumas, publicado en 1955; ese lugar sería finalmente para Cuentos de circunstancias, que apareció en 1958, y donde Ribeyro inaugura oficialmente la dimensión fantástica de su obra con «La insignia» y «Doblaje», curiosamente escritos en la misma época de los Cuentos olvidados y, por lo tanto, también otros posibles candidatos de ese ahora imposible Sonambulario ${ }^{5}$.

Al igual que la de Ribeyro, la protohistoria cortazariana está también plagada de relatos no miméticos, incluso algunos de ellos («Llama el teléfono, Delia», «Bruja») aparecieron publicados en diarios argentinos en su momento. Asimismo, el resto — con la excepción de «Estación de la mano», que el escritor recuperó para La vuelta al día en ochenta mundos (1967) — nunca fueron rescatados en posteriores publicaciones. Las razones que llevaron a Cortázar a prescindir de estos cuentos nos son desconocidas, pero puede aventurarse que, según dejan entrever sus cartas, primero por problemas editoriales y después por su propia voluntad, fueron dejados de lado por el autor: «Esos cuentos me pesan demasiado sobre los hombros, y quiero lanzarlos antes de convencerme del todo de que son malos» (2012: 230), escribe en una carta fechada el 21 de julio de 1945.

Como en el caso de los Cuentos olvidados de Ribeyro, la colección de relatos La otra orilla fue publicada póstumamente como parte del primer volumen de Cuentos completos publicado por Alfaguara en 1994. El título del libro parece referirse, más que al paisaje marino, al «lado nocturno de la realidad», un «paisaje interior, implícito, cuyas emanaciones externas son los monstruos, brujas, vampiros, fantasmas, etc. que pueblan la fantasía y constituyen la materia narrativa de este libro» (De Mora, 2002: 52). La colección está compuesta por trece cuentos escritos entre 1937 y 1945, los cuales aparecen divididos en tres secciones donde ya se observan las ideas y motivos que el autor desarrollará en sus posteriores obras: la primera de ellas, Plagios y traducciones, ilustra con ironía el reconocimiento honesto de su condición de joven escritor, así como un guiño a sus maestros del género; la tercera, Prolegómenos a la Astronomía, agrupa los relatos más alegóricos del conjunto con un pie en la ciencia ficción y otro en la poesía. Con todo, es la segunda sección, Historias de Gabriel Medrano ${ }^{6}$, la que mejor encierra la poética de lo fantástico que el escritor cultivará posteriormente. Compuesta por cuatro cuentos, a continuación analizaré tres de ellos («Retorno de la noche», «Mudanza» $\mathrm{y}$ «Distante espejo») en relación con «La huella» $\mathrm{y}$ «El cuarto sin numerar» de Julio Ramón Ribeyro, ya que el cuarto relato, «Bruja», rompe los patrones de lo fantástico para encasillarse mejor bajo la etiqueta de lo maravilloso.

Publicado originalmente en la revista limeña Letras Peruanas en febrero de 1952, «La huella» es el segundo de los seis relatos que componen el grupo de los Cuentos olvidados de Ribeyro. El cuento nos presenta a un hombre que persigue un rastro de sangre que termina por dirigirlo hasta su propia habitación, donde, antes de abrir la puerta, escucha el desplome de un cuerpo sobre su cama y comprende al fin «que en el interior de su habitación acababa de producirse el espectáculo de su propia

\footnotetext{
${ }^{5}$ Es importante ubicar también aquí el cuento «Demetrio», escrito en 1953, pero que no aparecería publicado hasta 1977 como parte del tercer tomo de La palabra del mudo.

${ }^{6}$ El uso de un heterónimo no llama tanto la atención en una época en la que Cortázar firmaba aún sus textos como Julio Denis. Este nombre, además, bautiza a uno de los personajes de su novela Los premios (1960).
} 
muerte» (Ribeyro, 2010: 22). La expresión de la vida en «La huella» aparece más ligada en el cuento a esa sangre que se escapa que a quien la persigue de una manera frenética, pero con la misma libertad que la de una sombra. La huella del cuento a la que se refiere el título, por lo tanto, no es ese rastro de sangre que deja el moribundo como la propia representación de esa misma persona que ha quedado en el pasado, desfasada.

La experimentación consciente de la propia muerte nos permite establecer una línea de conexión entre este cuento y «Retorno de la noche» de Julio Cortázar. En dicho cuento, escrito en 1941, el protagonista de la historia, Gabriel, tras soñar que se encontraba fatalmente enfermo, despierta y busca en su habitación un espejo que lo conforte: «Y entonces me vi, pero no a mí mismo. Es decir no me vi ante el espejo. Ante el espejo no había nada. Iluminado crudamente por el velador estaba el lecho y mi cuerpo yacía en él, con un brazo desnudo colgando hasta el suelo y la cara blanca, sin sangre» (Cortázar, 2004: 74). Tras reponerse, modela las facciones de su hasta entonces rostro y alisa sus cabellos con la intención de despertar a su abuela para darle la noticia. Al estar ante ella, sin embargo, las dudas le impedirán mantener su decisión, por lo que regresa a su cuarto tras sostener con ella solo una conversación banal. La mañana lo sorprende de nuevo en su cama, pero su recuperada tranquilidad durará poco, pues no solo la abuela aludirá a la conversación de aquella noche, sino que él mismo observará en el espejo de su cuarto su cabello cuidadosamente peinado, «como si alguien lo hubiese alisado durante la noche» (Cortázar, 2004: 82).

En ambos casos se puede afirmar que se trata de las primeras variantes del motivo del doble en la obra de ambos autores bajo el uso del tópico del fantasma: «el signo de la dualidad entre el cuerpo y el alma, lo material e inmaterial» (Honores, 2014: 64). Así, mientras las revelaciones finales en «Retorno de la noche» no dejan lugar a la duda, la frase con la que empieza «La huella» ya menciona de una manera muy sutil el momento en el que se produce el desdoblamiento entre el cuerpo (representado por la sangre) y el fantasma (el innominado protagonista de la historia): «Una mancha negra sobre el suelo lo hizo detenerse súbitamente, con la fuerza de un impacto que hubiera recibido a mansalva» (Ribeyro, 2010: 20).

Precisamente el tema del doble nos permite trazar un puente entre estos cuentos $\mathrm{y}$ «El cuarto sin numerar» de Ribeyro y «Mudanza» de Cortázar, también de las mismas colecciones. En ambos relatos, el objeto de lo fantástico sigue siendo el mismo: el ser humano; si bien en estos casos el desdoblamiento del personaje se relaciona también ahora con alteraciones en el espacio y el tiempo. Hay que recordar que una de las características definitorias de lo fantástico moderno es la evolución del espacio de simple recipiente del evento fantástico (tradicionalmente la figura de lo otro, como el fantasma en los cuentos anteriores) al de «elemento activo en la construcción de la transgresión fantástica» (García, 2013: 115), como sucede en los cuentos que se verán a continuación.

En el relato de Ribeyro, publicado en 1952, se narra la fijación de un hombre llamado Raúl con una vieja casa de edificios en la que no puede evitar siempre detenerse. Una tarde, sin poder contenerse más, va atravesando los cuartos de dicha vivienda y, sin notarlo, su personalidad va cambiando mientras persigue sin saberlo el sonido de un gramófono que lo lleva frente a un cuarto sin numerar. 
Dentro del cuarto los cambios se acentúan; así, la música que lo llevó hasta allí ya no le gusta e incapaz de parar el gramófono termina por romper el vinilo. En ese momento, una mujer que le parece conocida le pide que se acueste a su lado, lo que él hace; luego, ya en la cama, al intentar acariciarla se da cuenta de que sus manos no son las suyas y termina huyendo. Tras salir del edificio, Raúl encontrará en su bolsillo el pedazo del vinilo roto, y después de comprobar que este calza perfectamente con otro de su colección, no solo entenderá que la experiencia que acaba de vivir ha sido verdadera, sino que recordará que la música que provenía del gramófono era la que le cantaba su madre cuando era niño.

En «El cuarto sin numerar», por lo tanto, se ha producido un viaje al pasado del de donde Raúl ha regresado con un pedazo de vinilo, lo que simboliza la recuperación de su memoria. Lo fantástico, sin embargo, no solo está en la posibilidad de este viaje, sino que no ha sido Raúl quien ha viajado al pasado, sino solo su mente, que, por un momento, ha pasado a ocupar el cuerpo de su padre; lo que no solo explicaría tanto los cambios psicológicos como físicos que aparecen en el relato, sino que se podría suponer que la mujer que le recordaba a alguien no sería otra que su madre.

Esta transmigración nos lleva a la de «Mudanza», un cuento de Cortázar fechado en 1945 en el que asistimos a la mudanza literal de una persona al cuerpo de otra, proceso que se desarrolla a lo largo de una noche y en el que el protagonista de la historia, Raimundo Velloz, va percibiendo poco a poco cambios tanto entre sus familiares como en la misma configuración del espacio de su vivienda, hasta despertar un día, ya como Jorge Romero, y recibir en la puerta de su nueva casa a la que hasta ayer era su hermana, María Velloz, sin poder reconocerla. Mantengo la extensa cita que cierra el relato, injustamente ignorado por la crítica ${ }^{7}$, al ser uno de los mejores ejemplos de terror en los cuentos fantásticos de Cortázar:

Ella le alcanza la mano con el gesto maquinal y necesario del saludo. Raimundo espera un instante, espera que ocurra lo que debe ocurrir, pero como su hermana sigue con la mano tendida y nada sucede, alarga su diestra y el hacerlo le cuesta menos de lo que habría pensado. Repentinamente le parece que está bien, sería estúpido gritar que ella es María y que... Solamente piensa que podría haberlo dicho; lo piensa pero sin sentirlo. No lo siente para nada, solamente un pensamiento como tantos que uno tiene. Hasta quién sabe si lo ha pensado. Al contrario, algo le nace que lo conforta y lo alegra de que le hayan presentado a la señorita María Velloz. Si uno no conoce a alguien, es justo que se lo presenten (Cortázar, 2004: 103).

Por otra parte, una convergencia de los tópicos fantásticos presentes en los cuatro cuentos antes analizados la encontramos en «Distante espejo» de Cortázar, cuento escrito en 1943 y también parte de La otra orilla. Aquí el personaje, en su tranquila vida como profesor en una provincia de Argentina, descubre cómo su pequeño cuarto de estudio — con él dentro - puede estar a la vez en dos sitios diferentes. El impulso que llevó al personaje de Ribeyro de «El cuarto sin numerar» —y en su manera al perseguidor de «La huella»— a detenerse una y otra vez frente a una casa de edificios aparece en «Distante espejo» bautizado con el nombre de «estado Tupac-Amarú» ${ }^{8}$ y consiste en una rara atracción

\footnotetext{
${ }^{7}$ Uno de los pocos análisis del cuento se encuentra en el artículo de Vázquez (2010). Allí, la autora encuentra una posible referencia al mito de las Moiras en las mujeres de «Mudanza», si bien «en este caso sólo una, la abuela, hile y las tres no sean hermanas, sino abuela, madre e hija; tres generaciones que, sin embargo, evocan el transcurso de la vida» (Vázquez, 2010: 132).

${ }^{8}$ No he encontrado referencias sobre un estado con ese nombre. Aparentemente, Cortázar ironizó sobre la muerte de Túpac Amaru, cuyo verdadero nombre era José Gabriel Condorcanqui, quien, tras liderar la más importante rebelión indígena del
} 
que en el relato cortazariano hace irresistible al protagonista no seguir su camino y dirigirse, en este caso, hasta la casa de una colega suyo sin poder evitar entrar. Dentro queda sorprendido por una disposición y amueblamiento que son idénticos a los de la casa donde se hospeda, pero sobre todo le llama la atención una puerta similar a la de su propia habitación, a la que decide entrar: «Era [...] mi cuarto de trabajo. Entera y absolutamente mi cuarto de trabajo. Tan entera y absolutamente que, para darle la perfección total, estaba yo sentado en la mesa leyendo la Biblia de Lutero puesta en su atril de madera» (Cortázar, 2004: 110) .

Como antes en «El cuarto sin numerar» $\mathrm{y}$ «Mudanza», nos encontramos ante un espacio que escapa a cualquier tipo de clasificación, lo que en el relato del escritor peruano queda también simbolizado con la ausencia de un número en la puerta. De igual manera, el personaje de Cortázar también hace de espectador de su propia vida, si bien la escena está marcada por una absoluta cotidianidad. Asimismo, en «Distante espejo», se observa el caso de un espacio que no solo funciona como ambiente donde se desarrolla el evento fantástico, sino como participante del mismo; a través de ellos, tanto Cortázar como Ribeyro hacen referencia a la propia inseguridad del individuo frente a una realidad que ya no se reconoce unívoca y en la que es imposible recurrir a cualquier orientación.

Si ponemos los cuatro cuentos en contexto, se trata de relatos que Cortázar escribió entre los veinte y treinta años y que Ribeyro publicó con poco más de veinte. En el caso de Cortázar, los cuentos pertenecen a la época en que fue profesor en Chivilcoy y Mendoza, en el interior de Argentina; precisamente en «Distante espejo» aprovecha su propia experiencia como docente en Chivilcoy para exponer una vida «tan poco atrayente y los intereses culturales de sus habitantes tan escasos que al escritor no le quedó más remedio que refugiarse en la lectura»(De Mora, 2002: 49). Ribeyro, en cambio, se debatía por ese entonces entre terminar sus estudios de Derecho o ser escritor. Una anotación en su diario por esos días señala su encrucijada: «iTienes acaso inventiva, talento creador, clarividencias o fuerza dramática? No, no tienes de eso. Y así quieres vanagloriarte de hallazgos y así quieres escribir y así continuar alimentando sueños de literatura. ¿Hasta cuándo? ¿Por qué perseveras en una empresa tonta, ajena y sin porvenir?» (2003: 12; 1/04/1951).

En ese sentido, en los cinco cuentos anteriores podemos observar la búsqueda de unos protagonistas por recomponer una imagen de su yo: la sangre en «La huella», el vinilo roto en «El cuarto sin numerar» o el propio cuerpo en «Retorno de la noche», «Mudanza»y «Distante espejo» son una metáfora del vacío existencial en que viven los protagonistas e incluso los mismos escritores. Se trata, por lo tanto, de la clase de cuentos que, en palabras de Ángel Esteban, «se inscriben en la línea de Kafka, Borges, Monterroso, Arreola, y que corroboran la inestabilidad ideológica y existencial de

siglo XVIII, fue tomado prisionero y condenado a morir descuartizado vivo por cuatro caballos que, sujetos a sus extremidades, corrían en direcciones opuestas.

${ }^{9}$ Una escena similar, como ha señalado acertadamente ya Carmen de Mora, aparece en Le Horla (1886) de Maupassant, obra que se menciona además explícitamente en el cuento. El escritor francés, por su parte, es uno de los autores a los que Ribeyro rinde un sutil homenaje en «El libro en blanco» y a quien señala como una influencia directa al escribir el cuento fantástico «El carrusel» (Ribeyro, 2015: 321). 
toda esta generación de escritores preocupados por la condición humana, y a la vez carentes de soluciones definitivas» (1998: 62).

Si los relatos de Ribeyro son producto de las circunstancias de un joven escritor frente a los riesgos de una elección existencial, el caso de Cortázar no es muy distinto. El escritor argentino pasa por un momento de tránsito en su vida, pues son los años preparatorios para su mudanza a París. Su vida de profesor en provincia la resume en una carta bajo las siguientes líneas: «Después de haber abandonado Chivilcoy bajo vehementes sospechas de comunismo, anarquismo y trotskismo, he tenido el honor de que en Mendoza me califiquen de fascista, nazi, sepichista, rosista y falangista. Ambas cosas (las de Chivilcoy y Mendoza) con tanto fundamento como podría ser la de llamarme sauce llorón, consola Chippendale o Wee Willie Winkie» (2012: 229). Así, el agotamiento vital de su experiencia provinciana no solo es palpable en sus cartas: sus propios relatos simbolizan la incomodidad de la situación actual del escritor.

Cortázar y Ribeyro coincidieron en París desde 1960 hasta la muerte del escritor argentino en 1984. Para Ribeyro, Cortázar fue uno de los pocos escritores con quienes mantuvo una cercanía durante su estadía en la capital francesa. Alusiones a esta relación aparecen en su diario y cartas, pero es en una entrevista a Fernando Ampuero donde Ribeyro da más datos del alcance de esta relación: «Con el único que tuve contacto y amistad fue con Julio Cortázar. Era un hombre muy cordial y sencillo; muy amable, sobre todo, con los escritores jóvenes. [...] Era un tipo formidable, imaginativo y brillante. En una ocasión, en que hablábamos de un escritor que él juzgaba anticuado, me dijo que cuando abría sus libros todas las letras salían volando, como una nube de polillas» (en Ampuero, 2012: 162) ${ }^{10}$.

En suma, mientras que, en el caso de Cortázar el proyecto de un libro con relatos fantásticos sí llega a nosotros con Bestiario, Sonambulario y lo fantástico es un camino que, salvo contadas excursiones, Ribeyro finalmente prefiere evitar. Pese a ello, los cuentos de la protohistoria de ambos no solo comparten la condición de ser las primeras incursiones de dos jóvenes escritores dentro del ámbito de lo fantástico, sino que en ambos ya se observan las claves que redefinirán el cuento fantástico hispanoamericano del siglo XX.

\section{Referencias bibliográficas}

AMPUERO, F. (2012): «El enigma de la transparencia», en Gato encerrado. Lima, Punto de lectura, pp. 156-201.

CORTÁzar, J. (2004): Cuentos completos / 1. Buenos Aires, Punto de lectura. (2012): Cartas 1934-1954. Buenos Aires, Alfaguara.

DE MoRA, C. (2002): «La protohistoria literaria de Cortázar: La otra orilla», La Licorne, núm. 60, pp. 47-69.

Esteban, Á., ed., (1998): «Introducción», en J. R. RIBEYRO, Cuentos: Antología. Madrid, EspasaCalpe, pp. 9-66.

\footnotetext{
${ }^{10}$ Ribeyro recuperaría esta anécdota y la convertiría en uno de los aforismos de su libro Dichos de Luder (2018: 30).
} 
GARCÍA, P. (2013): «El espacio como sujeto de la transgresión fantástica en el relato "Los palafitos" (Ángel Olgoso, 2007)», Pasavento. Revista de Estudios Hispánicos, vol. I, núm. 1, pp. 113-124. GonzÁlez Montes, A. (2010): El mundo de la literatura en Sólo para fumadores de Ribeyro. Tesis, Universidad Nacional Mayor de San Marcos, disponible en http://cybertesis.unmsm.edu.pe/ bitstream/handle/cybertesis/1348/Gonzalez_ma.pdf [29-03-2018].

HONORES, E. (2014): La civilización del horror. el relato de terror en el Perú. Lima, Editorial Agalma. LOAYZA, L. (1993): «Regreso a San Gabriel», en El sol de Lima. México, Editorial Fondo de Cultura Económica.

LuChting, W. (1988): Estudiando a Julio Ramón Ribeyro. Madrid/Frankfurt, Iberoamericana/Vervuert.

MARTíneZ, J. M. (2008): «Los cuentos fantásticos de Julio Ramón Ribeyro: taxonomías y recepción», Revista de Crítica Literaria Latinoamericana, XXXIV/67, pp. 255-272.

MARTínez SALAZAR, E. y YELIN, J., eds. (2013): Kafka en las dos orillas: antología de la recepción crítica española e hispanoamericana. Zaragoza, Prensas de la Universidad de Zaragoza.

Minardi, G. (2002): «La dimensión fantástica», en La cuentística de Julio Ramón Ribeyro. Lima, Fondo Editorial de la Pontificia Universidad Católica del Perú, pp. 67-93.

NARbona, R. (2016): «Los cuentos olvidados de Julio Ramón Ribeyro», Revista de libros, disponible en http://www.revistadelibros.com/blogs/viaje-a-siracusa/los-cuentos-olvidados-de-julioramon-ribeyro [22-03-2018].

RibeYro, J. R. (2003): La tentación del fracaso. Barcelona, Seix Barral.

_ (2007): Prosas apátridas. Barcelona, Seix Barral.

- (2010): La palabra del mudo. Barcelona, Seix Barral.

- (2015): Las respuestas del mudo. Ed. J. Coaguila. Lima, Revuelta Editores.

- (2018): Dichos de Luder. Lima, Revuelta Editores.

RoAs, D. (2011): Tras los límites de lo real. Una definición de lo fantástico. Madrid, Páginas de Espuma.

Rodero, J. (2015): «Un inventario de enigmas. Los cuentos fantásticos de Julio Ramón Ribeyro», Ínsula. Revista de letras y ciencias humanas, núm. 826, pp. 22-25.

RodRíGUEZ PEQUEÑO, J. (1991): «Referencia fantástica y literatura de transgresión», Tropelías. Revista de Teoría de la Literatura y Literatura Comparada, núm. 2, pp. 145-156.

SusTi, A. (2013): «La encrucijada de lo fantástico: los primeros cuentos de Julio Ramón Ribeyro», Lienzo, núms. 33/34, pp. 85-117.

VANDOORNE, P. (2011): «Bibliotecas y voces imposibles: dos casos fantásticos en la literatura peruana del siglo XX». Tesis, Pontificia Universidad Católica del Perú, disponible en http://tesis.pucp.edu. pe/repositorio/handle/123456789/7774 [23/03/2018].

VArgas Llosa, M. (1996): «Ribeyro y las sirenas», en I. P. Márquez y C. Ferreira, eds., Asedios a Julio Ramón Ribeyro. Lima, Fondo Editorial de la Pontificia Universidad Católica del Perú, pp. 261-264. 
16 Tropelías. Revista de Teoría de la Literatura y Literatura Comparada, 32 (2019)

Gustavo Quichiz Campos

VÁZQUEZ, N. (2010): «De la "araña del aire” a los "piolines": las transformaciones de Aracné en Julio Cortázar», Amaltea. Revista de mitocrítica, núm. 2, pp. 123-142.

VIDAL, L. F. (1975): «Ribeyro y los espejos repetidos», Revista de Crítica Literaria Latinoamericana, núm. 1, pp. 73-88. 